\title{
Outline of the Unit 4-1 train of Our Higashi Niigata Thermal Power Station And Operating Records
}

\author{
N.Endou, N.Sakuma, S.Ohno, Y.Nishimura, N.Fujita \\ Tohoku Electric Power Co.,Inc.,Sendai,Miyagi,Japan
}

\begin{abstract}
With the set-in of the 21st century, energy and environmental problems such as energy security and global warming are sparking much greater controversy as burning issues that sways the fate of human beings. One of technologies presently available to deal with these issues is combined cycle power generation facility that can enhance the efficiency of power generation.

At Tohoku Electric Power Company, we successfully developed and introduced Japan's first large-capacity combined cycle power plant (Higashi Niigata Thermal Power Plant Unit 3) in 1985. Going through experience in the operation and maintenance of this plant, we set about R\&D on a high-efficiency gas turbine in 1987.

The Unit 4-1 train of our Higashi Niigata Thermal Power Station was constructed by applying the results of this high-efficiency gas turbine $R \& D$ program, and by applying expertise we gained from the planning, construction, operation and maintenance of the Unit 3 train.
\end{abstract}

Keywords: Combined Cycle, Gas turbine, Large-capacity, High-efficiency

\section{Background of Development}

With the set-in of the 21 st century, energy and environmental problems such as energy security and global warming are sparking much greater controversy as burning issues that sway the fate of human beings.

Technologies presently available to deal with these issues are mostly related to power generation. Typical technologies aimed at enhancing the efficiency of power generation include combined cycle power generation facilities that are a combination of gas turbine and steam turbine.

A combined cycle power generation facility can increase thermal efficiency to a significant degree by raising gas temperatures at the inlet of the gas turbine, a main component of this facility. Combined cycle power generation is not only cost-efficient but also the technology that can contribute greatly to reducing the emissions of carbon dioxide, which is believed to be one of the causes of global warming.

At Tohoku Electric Power Company, we successfully developed and introduced Japan's first large-capacity combined cycle power plant eighteen years ago. Going through experience in the operation and maintenance of this plant, we learned that the combined cycle power generation technology had a potential for further enhancing thermal efficiency. And in 1987, we set about research and development on a high-efficiency gas turbine, a main engine of the combined cycle power generation plant.

Gas turbine technological levels in those days were such that the Unit 3 train of our Higashi Niigata Thermal Power Plant (the "Unit 3 train") attained the highest level of 1150degC.
Around 1987, electric power companies in Japan and foreign countries were working to develop commercial gas turbines in order to attain the gas turbine inlet gas temperature of $1300 \mathrm{degC}$.

We raised this gas turbine inlet gas temperature target a step higher to over $1450 \mathrm{degC}$, with the aim of developing a gas turbine attaining a hoped-for $50 \%$ in plant thermal efficiency. We launched the advanced gas turbine research and development program designed to develop elemental technologies necessary for making the technology fit for practical use.

The Unit 4-1 train of our Higashi Niigata Thermal Power Station (the "Unit 4-1 train") was constructed by applying the results of this high-efficiency gas turbine research and development program, and by applying expertise we gained from the planning, construction, operation and maintenance of the Unit 3 train.

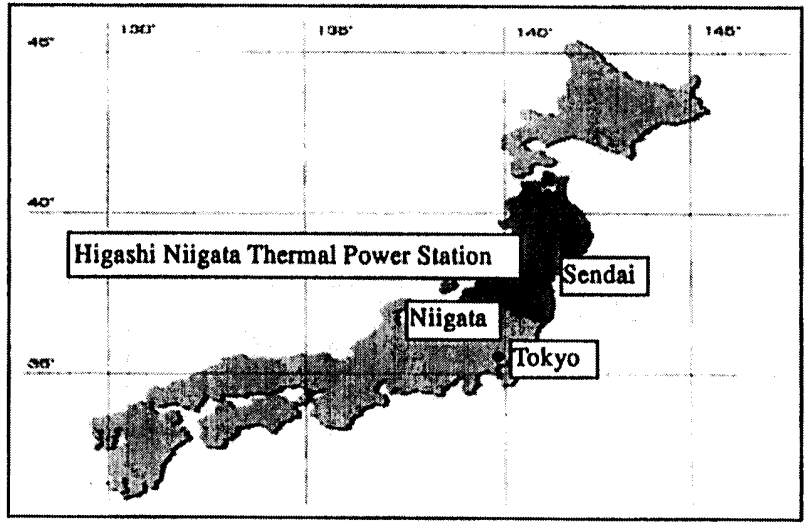

Fig. 1 Site of Higashi Niigata Thermal Power Station 
Because a gas turbine, adopted in the Unit 4-1 train, was a key component for improving plant thermal efficiency, the turbine inlet gas temperature ("TIT") was raised substantially from $1154 \mathrm{deg} C$ in the Unit 3 train to $1450 \mathrm{deg} C$ the world's highest level for commercial gas turbines.

The unit output of this gas turbine reached the world's highest level of $270 \mathrm{MW}$, making it possible to increase the output of one single series of the multi-shaft type combined cycle power generating facility to $805 \mathrm{MW}$ (at atmospheric temperature of $-1 \operatorname{degC}$ ).

In a project to put this gas turbine to practical use, we started elemental tests jointly with Mitsubishi Heavy Industries, Ltd., our partner, solved a number of problems by carrying out various demonstration tests and shop tests, and finally developed this gas turbine by making the most of users' expertise and manufacturers' technologies.

In April 1996, we started the construction of the plant. In October 1998, the gas turbine was started up for test operation. In May of the following year, the gas turbine recorded the world's highest plant thermal efficiency of $50.6 \%$ (gross thermal efficiency; higher heating value (HHV) basis). On July 8, 1999, the gas turbine went into commercial operation.

Now that we broke the thermal efficiency barrier of $50 \%$ (HHV basis) with the world's largest power generation facility and created an environmentally acceptable energy-saving plant by overcoming numerous difficulties, we received the Japan Industrial Technology Award, the Prime Minister Prize, and the Japan Society of Mechanical Engineers' Prize for Technology in April 2000. In June of the same year, we were awarded the Japan Society of Energy and Resources' Prize for Technology.

Following are the characteristics of the Unit 4-1 train, the results of test operations, and the operational data.

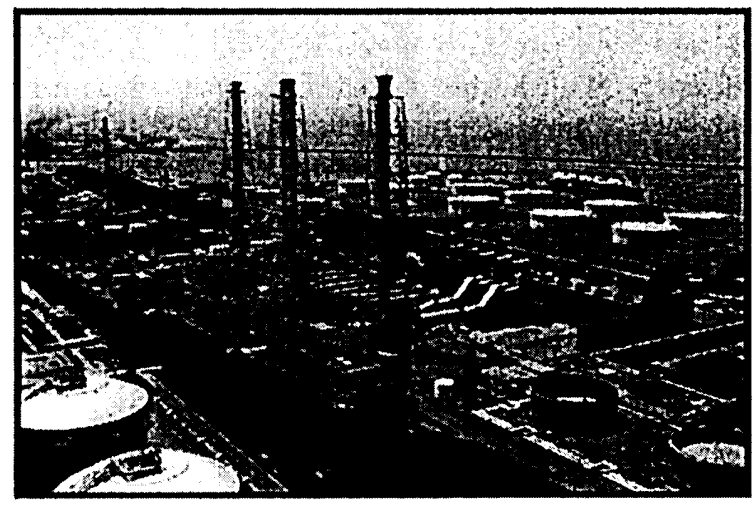

Fig. 2 Full View of Higashi Niigata Thermal Power Station

(Unit 4-1 in front and Unit 3 in the rear)

\section{Outline of the High-Efficiency Gas Turbine Research and Development Program}

Aiming to develop a gas turbine with TIT of over $1450 \mathrm{degC}$ to allow the plant to attain over $50 \%$ in thermal efficiency, we started in 1989 the advanced gas turbine research and development program (the "AGT research and development program").
Under the AGT research and development program, we worked on the development of elemental technologies necessary to develop a workable advanced gas turbine jointly with three leading Japanese gas turbine manufacturers. The program lasted as long as six years and involved activities ranging from the development of sophisticated technologies to their verification, focusing on the following topics.

With future expansibility in mind, we set a target at $1500 \mathrm{deg} C$ in TIT in the development of the following elemental technologies:

- High-performance cooling blades

- Heat-resistant material for turbine moving and stationary blades

- High-temperature and low NOx combustors

Prospects looked better for the development of elemental technologies necessary to build a workable high-efficiency gas turbine. We successfully developed the state-of-the-art gas turbine that incorporated these latest elemental technologies. Incorporating this gas turbine, we started in April 1996 the construction of the Unit 4 trains of our Higashi Niigata Thermal Power Station.

\section{Outline of the Power Generation Facility}

\section{1 Outline of the Unit 4-1 train power generation} facility

In July 1999, the Unit 4-1 train plant with a total capacity of $805 \mathrm{MW}$, which is a half capacity of the full train, went into commercial operation. The capacity was increased to 826MW in April 2001.

The Unit 4-1 train is a multi-shaft combined cycle power generating facility that is composed of two gas turbines, two exhaust heat recovery steam generators, and one steam turbine, and is capable of producing electricity with great efficiency and at large capacity output. (See Fig.3)

Specifications for the main components of the Unit 4-1 train are as follows.

Table 1.

Specifications for Main Components of Unit 4-1 train

\begin{tabular}{|c|c|c|}
\hline (1) & $\begin{array}{l}\text { Gas turbines } \\
\text { Type } \\
\text { Output } \\
\text { Inlet pressure } \\
\text { Inlet temperature } \\
\text { Number of revolutions }\end{array}$ & $\begin{array}{l}2 \text { units } \\
\text { Open, simple cycle, single } \\
\text { shaft type } \\
275 \mathrm{MW} \text { (at }-1 \mathrm{degC}) \\
1.9 \mathrm{MPa} \\
1,450 \mathrm{degC} \\
3,000 \mathrm{rpm}\end{array}$ \\
\hline (2) & $\begin{array}{l}\text { Heat recovery boilers } \\
\text { Type } \\
\text { Evaporation } \\
\text { Outlet pressure } \\
\text { Outlet temperature } \\
\end{array}$ & $\begin{array}{l}2 \text { units } \\
\text { Exhaust heat recovery, triple } \\
\text { pressure type } \\
281 / 75 / 65 \mathrm{t} / \mathrm{h} \\
14.1 / 5.2 / 0.64 \mathrm{MPa} \\
569 / 295 / 270 \mathrm{degC} \\
\end{array}$ \\
\hline (3) & $\begin{array}{l}\text { Steam turbine } \\
\text { Type } \\
\text { Output pressure } \\
\text { Inlet pressure } \\
\text { Inlet temperature } \\
\text { Number of revolutions }\end{array}$ & $\begin{array}{l}1 \text { unit } \\
\text { Tandem compound, } 2 \text {-flow } \\
\text { exhaust, reheat mixed } \\
\text { Condensate type } \\
276 \mathrm{MW} \\
13.7 / 4.1 / 0.49 \mathrm{MPa} \\
566 / 566 / 267 \mathrm{degC} \\
3,000 \mathrm{rpm}\end{array}$ \\
\hline
\end{tabular}




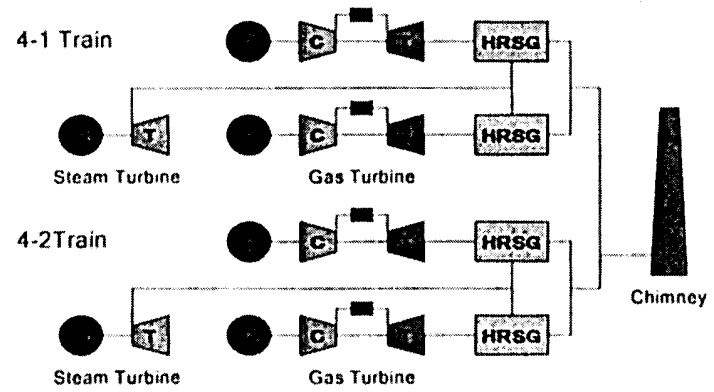

G:generater, C:compressor, T:turbine HRSG : heat recovery steam generator

Fig. 3 Schematic Diagram for Unit 4-1 Train of Higashi Niigata Thermal Power Station

\section{2 Gas turbine}

The high-efficiency gas turbine with TIT of $1450 \mathrm{degC}$ and capacity of $275 \mathrm{MW}$ (at design atmospheric temperature of - $1 \operatorname{deg} C)$, developed with the latest technologies, reflecting the results of the AGT research and development program, was adopted in the Unit 4-1 train. (See Fig. 4)

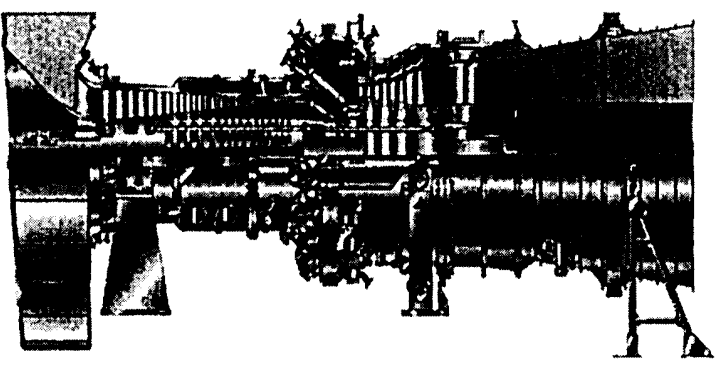

Fig. 4 Cross Section of $1450 \mathrm{degC}$ Gas Turbine

\subsubsection{Development and introduction of high-performance cooling blades}

Various high-performance cooling technologies, developed under the AGT research and development program, were adopted in a system for cooling first-stage moving and stationary blades that are exposed to the hottest combustion gas in order to obtain greater cooling efficiency.

The following cooling technologies were incorporated into the first-stage stationary blades that are operating under the harshest temperature conditions. (See Fig. 5)

The impingement (collision) cooling method is adopted to cool the inside surface of the blade while the pin fin cooling method is applied to cool the trailing edge of the blade in order to improve cooling efficiency. The outer face of the blade is cooled by the full film cooling system with a shower head and a shaped film cooling nozzle. The film cooling system is also adopted in the shroud so as to prevent the generation of a locally high-temperature area.

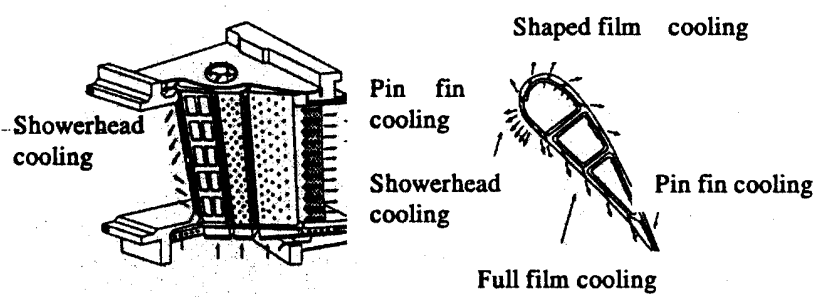

Fig. 5 High-Performance Cooling Structure of First-Stage Stationary Blade

In the first- and second-stage moving blades which are subject to centrifugal force as the machine turns at a high speed, in addition to harsh temperature conditions, the serpentine cooling structure is used in combination with a turbulence promoter to cool the inside of the blade. Moreover, the blade surface film cooling method with a shaped film is introduced in the outside of the blade in order to achieve greater cooling efficiency as compared with conventional method.

In the first- and second-stage moving and stationary blades, thermal barrier coating (TBC) is adopted in order to enhance the yield strength of material at high temperature. (See Fig. 6)

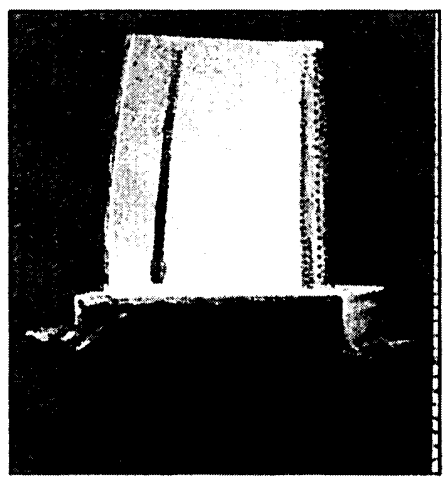

Fig.6 Thermal Barrier-Coated Moving Blade

By adopting these cooling and thermal barrier technologies, we successfully reduced the temperature of metal material in the high-efficiency gas turbine with TIT of over $1450 \mathrm{degC}$ down below the conventional level. We verified these new cooling technologies by carrying out element tests, and using the actual blade designed on the basis of data from element tests, carried out high-temperature blade lattice tests in a static ground.

Moreover, we manufactured a model turbine blade and tested it with a high-temperature demonstration unit (HTDU; see Fig.7) under actual operating conditions, thereby confirming the reliability of technologies before adopting them in an operational unit. 


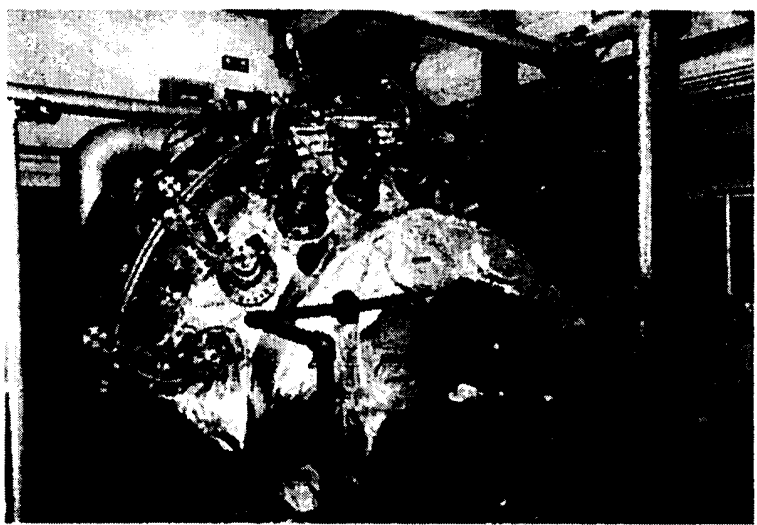

Fig.7 High-Temperature Demonstration Unit(HTDU)

3.2.2 Development and introduction of heat-resistant materials for moving and stationary blades

Because the commonly used conventional casting (CC) alloy was unsuitable for use in a TIT $1500 \mathrm{degC}$-class gas turbine, we decided to use directionally solidified (DS) alloy as blade material by controlling the direction of crystalline growth to prevent a grain boundary from appearing in a direction at which centrifugal force works. (See Fig.8)

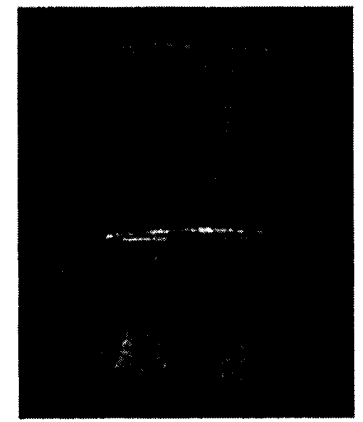

Fig.8 Directionally Solidified Moving Blade

Although this DS alloy had been used in small turbine blades of the aircraft jet engine, large blade precision casting technology was yet to be established. Therefore, it was considered difficult to use the DS alloy in commercial gas turbines when we were working on the development of the high-efficiency gas turbine.

Solving a number of problems encountered, we successfully developed viable DS alloy large blade precision casting technology jointly with manufacturers. We adopted this technology in the first- and second-stage moving blades in the high-efficiency gas turbine. (See Table 2.)

Compared with the conventional material, the strength of the newly developed material increased by approximately $50 \mathrm{deg} C$ in terms of metal temperature and by nearly $60 \%$ in terms of stress.

\subsubsection{Development and adoption of high-temperature and low NOx combustor}

Achieving combustion stability at high temperature and reducing NOx emissions were two different challenges with the conventional air-cooled combustors.
Table 2. Gas Turbine Blade Material

\begin{tabular}{r|c|l}
\hline & & Name of material \\
\hline $\begin{array}{r}\text { Stationary } \\
\text { blade }\end{array}$ & 1st stage & MGA2400 \\
\cline { 2 - 3 } & 2nd stage & MGA2400 \\
\cline { 2 - 3 } & 3rd stage & MGA2400 \\
\cline { 2 - 3 } & 4th stage & MGA2400 \\
\hline $\begin{array}{r}\text { Moving } \\
\text { blade }\end{array}$ & 1st stage & $\begin{array}{l}\text { CM247LC } \\
\text { (Directionally solidified material) }\end{array}$ \\
\cline { 2 - 3 } & 2nd stage & $\begin{array}{l}\text { CM247LC } \\
\text { (Directionally solidified material) }\end{array}$ \\
\cline { 2 - 3 } & 3rd stage & MGA1400 \\
\cline { 2 - 3 } & 4th stage & MGA1400 \\
\hline
\end{tabular}

In general, expanding the diffusion combustion range with good combustion stability will result in a rise in flame temperature to exponentially increase the concentration of NOx emissions.

Furthermore, in the conventional air-cooled combustors, because cooling air would flow into high-temperature combustion gas to cause a drop in TIT, flame temperature had to be raised to a level higher than necessary.

Therefore, we developed a new combustor capable of maintaining high temperature and lower NOx without spoiling combustion stability.

The newly developed combustor was based on the multi-nozzle low NOx combustor used in the conventional $1300 \mathrm{degC}$-class gas turbine, and various new technologies and their improvements were incorporated in it.

New technologies were adopted in the newly developed combustor for a number of reasons. First, new technologies were incorporated to further raise the pre-mixed combustion ratio (the ratio of pre-mixed combustion to pilot combustion) in order to prevent NOx emissions from increasing due to a rise in TIT. As a result, the premixed combustion ratio was successfully raised to approximately $95 \%$ without spoiling combustion stability. (See Fig. 9)

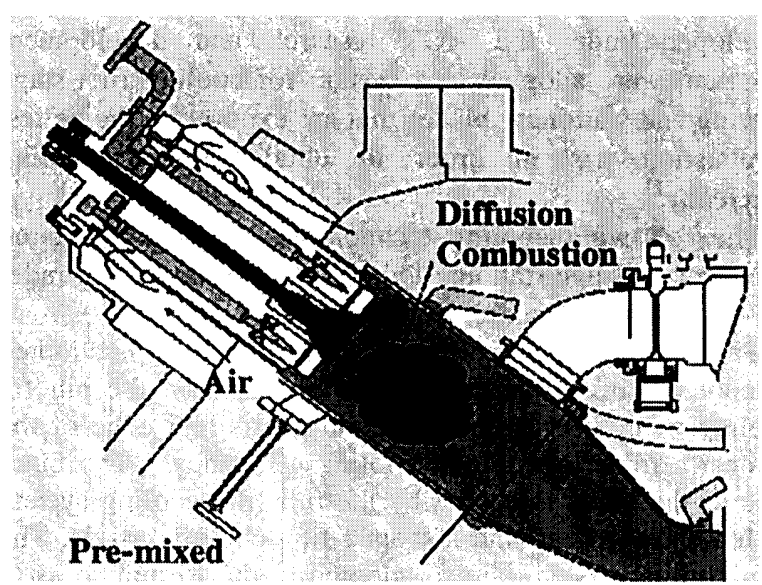

Fig.9 Expansion of Pre-mixed Combustion Ratio 
Secondly, the combustor wall steam cooling method was adopted for the first time in the world. This was the most salient feature of the newly developed combustor.

Instead of air, steam was used as a medium of cooling the combustor wall in order to minimize a drop in TIT. As a result, TIT alone was successfully raised while the flame temperature of the combustor was controlled to the existing level, and it became possible to hold the concentration of NOx emissions down to the conventional level. (See Fig. 10)
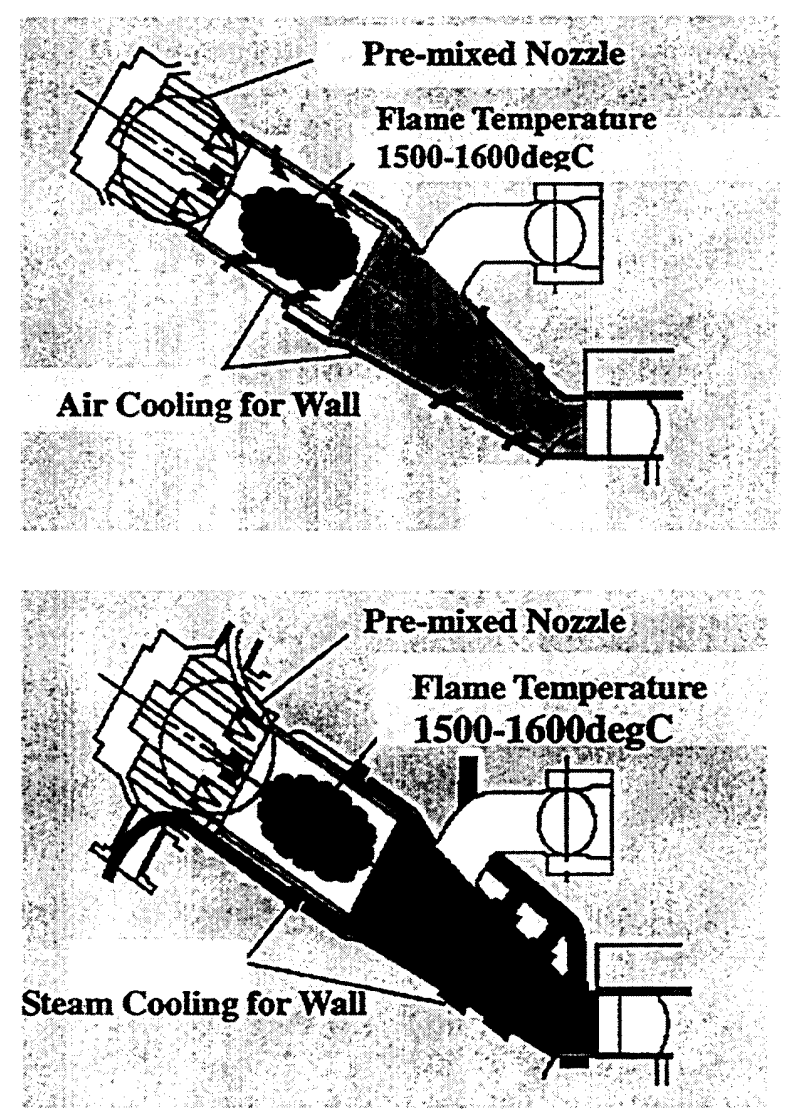

Fig. 10 Comparison between Air-Cooled Combustor and Steam-Cooled Combustor

\section{3 Exhaust heat recovery steam generator}

The vertical flow, exhaust heat recovery triple pressure steam generator was adopted. This steam generator has a good space factor.

Adoption of the vertical flow type made it possible to decrease the number of modules for carrying the unit to the site. While the horizontal flow type required three modules, the vertical flow type needed only two modules to be carried.

In consequence, sections to weld at the site were substantially decreased, thus contributing greatly to the shortening of a work period and to the improvement of safety and quality in installation work.

Moreover, the temperatures of both high-pressure steam and reheat steam were raised to $566 \mathrm{degC}$ for the first time as the combined cycle power generation steam generator. Thermal efficiency was increased as a result.

\section{4 Steam turbine}

The thermal efficiency of the steam turbine was increased by steam condition improvements, such as the use of high-temperature and high-pressure main steam, the introduction of a reheat cycle, and the introduction of reheat steam in low-pressure steam.

Moreover, the three-dimensional design was adopted in all of the high- and medium- pressure blades and in some low-pressure blades. In the final stage of the low-pressure turbine, a 40.5 -inch long blade was adopted. This blade was the longest ever installed in the combined cycle power generation facility. The aim was to improve the internal efficiency of the turbine.

\section{5 Central control room}

The ergonomic holistic design was adopted in the central control room to improve a working environment. The information intensive CRT one-touch operation system was adopted in a whole way to increase the ease of monitoring operation.

In addition, two 70-inch large screens were installed to share information.

In order to generally monitor all the facilities including the Unit 3 train, the Unit 3 and 4 train integrated supervisory control system having all monitoring functions was installed, affording an appreciable saving of labor for operations and plant monitoring.

\section{6 High-temperature parts control system}

With the startup of the Unit 4-1 train, the number of gas turbine high-temperature parts in the Unit 3 and 4 trains amounted to nearly 7000 . Controlling the remaining life and activity logs of these high-temperature parts would take thousands of man-hours. Therefore, the high-temperature parts control system was installed in order to streamline jobs involved in high-temperature parts.

The high-temperature parts control system was composed of three sections: the gas turbine parts inspection room semiautomatically performing inspections on high-temperature parts, the automated high-temperature parts warehouse automatically controlling, delivering and receiving high-temperature parts, and the high-temperature parts control support system supporting general control over the remaining life and activity logs of high-temperature parts.

The high-temperature parts control system allowed us to carry out inspection more accurately than we did manually. The automated warehouse enabled us to deliver and receive high-temperature parts more efficiently and control the activity logs of high-temperature parts more accurately and quickly. With this system, we established an advanced and economical quality control structure enabling us to avoid waste.

\section{Results of Shop Tests and Field Test Operations}

After the manufacturing of the gas turbine was completed, we carried out actual load tests on the gas turbine, a key component of the Unit 4-1 train, at manufacturers' factories in the spring of 1998. 
In actual load tests, we carried out special measurements at about 1500 points in order to closely examine the performance and reliability of the air compressors, combustors and turbines. As a result, we confirmed that the gas turbine had high efficiency and reliability as initially planned.

Subsequently, we carried the gas turbine to the site and the test operation of the Unit 4-1 train was begun.

In October 1998, we started the test operation of the first gas turbine. After the test operation of the second gas turbine, we put the combined cycle power generation facility into operation.

After various adjustments were made, we operated the plant at the authorized capacity of $805 \mathrm{MW}$ in February 1999. In May of the same year, we tested the performance of the plant and confirmed that it attained the planned performance.

During these field test operations, after shop actual load tests, we carried out special measurements of the metal temperature of high-temperature parts at about 500 points, and a high level of reliability was achieved.

\section{1 Plant thermal efficiency}

By carrying out plant performance tests, we confirmed that plant thermal efficiency met the planned values at various loads. In plant performance tests, conducted in May 1999, the plant recorded the world's highest thermal efficiency of $50.6 \%$ (HHV basis).

\section{2 Performance verification}

Following shop actual load tests, we chiefly measured the metal temperatures of high-temperature parts of the world's first TIT 1450degC-class gas turbine during field test operations, and verified in the field that the gas turbine showed high reliability and performance.

With special measurement carried out by attaching thermocouples to the steam cooling combustors, the first-stage turbine moving blade and first- and second-stage stationary blades, the metal temperatures of these components were measured.

Telemeters were also used to measure the metal temperature of the moving blade.

Concerning the combustors, we measured NOx and $\mathrm{CO}$ emissions, and unburned hydrocarbon (UHC), combustion vibration, and vibration stress, and verified that the combustors were highly clean and showed good combustion stability.

\section{Operating Records after Startup}

The Unit 4-1 train has been operating for nearly 21,265 hours since it went into commercial operation in July 1999 (operating hours were as of the end of fiscal 2001).

During this period, the Unit 4-1 train has been operating highly efficiently without shutdown while the combustors were inspected and components were examined and cleaned.

During fiscal 2001, the Unit 4-1 train attained a thermal efficiency of about $50 \%$ on the operational basis. By carrying out careful control, we expect that the Unit 4-1 train will be able to achieve a higher level of actual yearly thermal efficiency.

\section{Conclusions}

The TIT 1450degC gas turbine, developed by applying the results of the six-year advanced gas turbine research and development program, was incorporated into the Unit 4-1 train of the Higashi Niigata Thermal Power Station. We carried out twice inspection on the Unit 4-1 train, initial periodical inspection during a period from September to November 2000, secondary one from September to December 2002, and verified that the integrity of the components of the Unit 4-1 train was satisfactory

Although there was insignificant damage found, the main high-temperature parts such as the combustors and turbine blades were free of defects that might affect the operation of the plant. We verified that the high-temperature parts had long-term reliability. (See Fig. 11)

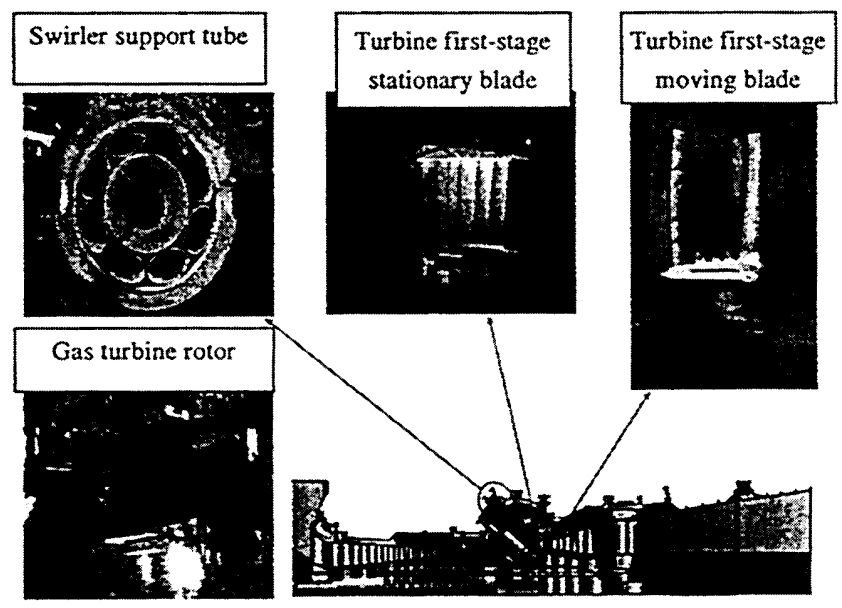

A cross section of the gas turbine

Fig. 11 Overview of High-Temperature Parts in Initial Periodical Inspection

In May 1999, we attained the world's highest plant thermal efficiency of $50.6 \%$ (HHV basis). Various test operations found that the Unit 4-1 train met the planned values satisfactorily. In July 1999, the Unit 4-1 train went into commercial operation. Since that time to the end of fiscal 2001, the Unit 4-1 train has been operating steadily for nearly 23,928 hours, with test operations included.

If the Unit 4 train of the Higashi Niigata Thermal Power Station operates at its full capacity of $1,610 \mathrm{MW}$ and attains a thermal efficiency of $50 \%$, it will be able to reduce LNG consumption by about 370,000 tons yearly and $\mathrm{CO}_{2}$ emissions by around $22 \%$ compared with the conventional LNG-fueled thermal power plants. The result means that this plant is environmentally acceptable.

With this plant, we have contributed greatly to a reduction in the power cost and in the emission of greenhouse gases. 